Atmos. Chem. Phys. Discuss., doi:10.5194/acp-2017-133, 2017

\title{
Stratospheric Aerosol Climatology over Ethiopia and Retrieval of its Size Distribution
}

\author{
Milkessa Gebeyehu Homa*1, Gizaw Mengistu Tsidu ${ }^{2}$, and Derese Tekestebrihan Nega ${ }^{1}$ \\ ${ }^{1}$ Jimma University, College of Natural Sciences, Department of Physics, Jimma, Ethiopia \\ ${ }^{2}$ Addis Ababa University, College of Natural Sciences, Department of Physics, Addis Ababa, Ethiopia \\ Correspondence to: Milkessa Gebeyehu Homa \\ (mikemen.homa@gmail.com)
}

\begin{abstract}
Stratospheric aerosols play significant role both positively and negatively in Earth's energy balance and climate change. Its main sources are particulate matters which arises from either of natural or anthropogenic activities. In the context of our country, Ethiopia, the stratospheric aerosol climatology has not been studied yet. However, Ethiopia is undergoing a boom of infrastructural development like increase of urbanization, which comes with a boom of development like building

5 and road constructions, expansion of industries, traffic density, etc, which contributes to air pollution and influences the solar radiation budget of the earth-atmosphere system, which in turn influences the climate on the surface of the Earth by different ways. Hence, this study aimed to provide the stratospheric aerosol climatology for nearly 21 years extending from Oct., 1984 to Sept., 2005. The study was carried out by defining the stratospheric region from the temperature profile of the study area provided by Stratospheric Aerosols and Gas Experiment II (SAGEII) instrument aboard on Earth's Radiation Budget Satellite (ERBS). Then, the data was filtered out over Ethiopian region at four aerosol channels and the optical depth is used as input to the Mie algorithm for aerosol size distribution (ASD) retrieval. Finally, it was observed that the spectral and vertical variation of the extinction is maximum between $17-25 \mathrm{~km}$ and the total column aerosol optical depth (AOD) temporal variation shows nearly steadily increasing trend with maximum variation during spring. Furthermore, from the ASD result it was observed that the maximum size distribution was in April. This paves a clue about their sources to be mechanical process on the ground and gas to particle conversion in the stratosphere with the dominant size distribution in the range of $0.452-0.525 \mu \mathrm{m}$ radius.
\end{abstract}

\section{Introduction}

Atmospheric aerosols are liquid or solid particulate matters suspended in the air. They are highly populated in the lower atmosphere. However, the mid-atmosphere aerosols play significant roles in the atmospheric sciences because of their contribution to the Earth's climate. Non-absorbing aerosols increase the albedo of the atmosphere and reduce the amount of solar radiation (short wave) reaching the surface, but if it is absorbing aerosols in the shortwave (SW) range of the spectrum, energy is directly transferred to the atmosphere, and the effect is heating of the atmosphere and cooling of the underlying surface (Tzanis C. and Varotsos C.A. , 2008).

The distribution of aerosols decreases with altitude and has a significant impact on the radiative balance and chemistry of troposphere (Chowdhary J. and Cairs B. , 2002). The sources of these particulate matters could be from anthropogenic or 
Atmos. Chem. Phys. Discuss., doi:10.5194/acp-2017-133, 2017

Atmospheric

Manuscript under review for journal Atmos. Chem. Phys.

Chemistry

Discussion started: 21 February 2017

(c) Author(s) 2017. CC-BY 3.0 License.

and Physics

Discussions

(c) (i)

natural activities at the surface or within the atmosphere. The presence of these particulate matters in the Earth's atmosphere has significant impact (both positively and negatively) either directly or indirectly on human activities in particular and life on Earth in general. In addition, aerosols scatter and absorb shortwave (solar) and long wave (thermal infrared) radiation, thereby perturbing the energy budget of the Earth-atmosphere system and exerting a direct radiative forcing (RF) which is a measure

5 of the net reduction or increase in the amount of surface-reaching or outgoing radiation due to total columnar aerosol burden (CCSP. , 2006), (Fu Q.. et al. , 1999).

Though this crude fact is there, in the context of our country, Ethiopia, the aerosol size distribution has not been studied yet for such long period. As Ethiopia is undergoing a boom of infrastructural development like increase of urbanization, which comes with a boom of development like building and road constructions, expansion of industries, traffic density, etc, which contributes to air pollution by different ways. One of this is solid material loading to the atmosphere, mostly of dusts and minerals. The accumulation of these particulate matters affects the country's solar energy budget (solar radiation reaching the surface of the Earth), health, visibility (on aviation industry), etc. Hence, it is the right time to give the right attention to air quality, holistic ground based solar energy potential prediction and climate change impacts as it is a night mare issues nowadays.

Therefore, this work is the first to provide a long term data analysis report on aerosol climatology in Ethiopia. Its main goal is to investigate vertical and seasonal distribution and annual mean values of aerosol optical depth over Ethiopia using the stratospheric aerosols and gas experiments (SAGE) II instrument boarded on Earth's radiation budget satellite (ERBS) extinction data for a period of approximately 21 years extending from Oct., 1984 to Sept., 2005. The vertical distribution of aerosols at different channels of SAGE II and spatial distribution are also discussed. The trend of column amount aerosol optical depth (AOD) and the monthly mean size distribution function of aerosols for some of the selected years are retrieved using Mie algorithm (King M.D. et al. , 1980).

\subsection{Sources and Removal of Atmospheric Aerosols}

It is usual practice to group aerosols by their origins: those produced as a result of naturally occurring geological processes; those produced as a result of human activity ('anthropogenic'); and those produced by biological processes ('biogenic'). Distinction is also often made between tropospheric and stratospheric aerosols, as those often share different sources and have different radiative effects (Sayer A.M. , 2006). After introducing the continuous atmospheric aerosol size distribution, Jung (1963) mentioned in (Hobbs P.V. , 1993), also classified them geographically into maritime, continental, and background aerosols and by size into Aitken $(0.001 \mu m-0.1 \mu m)$, large $(0.1 \mu m-1 \mu m)$ and giant $(>1 \mu m)$ radius particles. Whitby (1973) in (Hobbs P.V., 1993), introduced the terms nucleation mode $(0.001 \mu m-0.1 \mu m)$, accumulation mode $(0.1 \mu-1 \mu) m$ and coarse particle mode $(>1 \mu) \mathrm{m}$. The nucleation mode was produced by gas-to-particle conversion (GPC), the accumulation mode by coagulation and heterogeneous condensation, and the coarse mode by mechanical processes. Volcanic sources (like: Mt.Pinatubo eruption in 1991 and Mount St. Helens eruption in July 22, 1980) are globally significant in their influence on the stratosphere . 
Atmos. Chem. Phys. Discuss., doi:10.5194/acp-2017-133, 2017

Manuscript under review for journal Atmos. Chem. Phys.

There exists close relationship between atmospheric aerosols and the process of cloud formation and precipitation, implying a water cycle in the atmosphere would not be possible in the absence of aerosols. On the other hand, it is precisely this water cycle, made possible by aerosols that represents the most effective process for their removal from the atmosphere (Israel $\mathrm{H}$. and Israel G.W. , 1974). Some of the processes of removal of aerosols from the atmosphere include: Wet removal, dry removal, cloud formation, etc. The overall stratospheric aerosol cycle is shown in Fig.1 and discussed in (Thomason L. et al. , 2007).

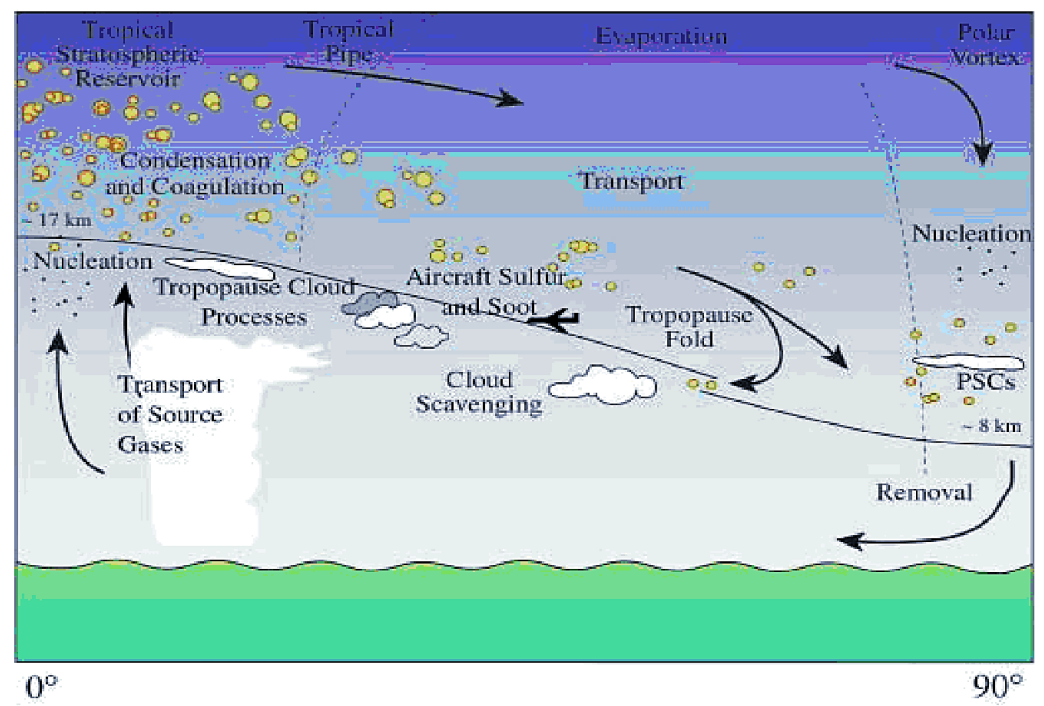

Figure 1. Schematics of overall stratospheric aerosol lifecycle (Thomason L.W. et al. , 2007)

\section{Methods}

In this study the secondary extinction data from SAGE II instrument aboard the Earth Radiation Budget Satellite (ERBS) which was launched in October 5, 1984 was used. The instrument was able to provide high quality measurements of ozone, nitrogen dioxide, water vapor, and profiles of aerosol extinction at wavelengths centered at 386,452,525, and 1020 nano meters from the mid-troposphere to as high as the lower mesosphere. All profiles are at $0.5 \mathrm{~km}$ vertical resolution. These products are nearly global in coverage, with data spanning from $80^{\circ} \mathrm{N}$ to $80^{\circ} \mathrm{S}$. The temporal coverage of SAGE II was from 5, Oct. 1984 to 8 , Sep. 2005.

SAGE II instrument views a small portion of the sun through the Earth's atmosphere during the spacecraft's sunrise and sunset (using limb occultation technique). Data are obtained from the attenuation of the sun light due to scattering and absorption by different atmospheric species. The spacecraft's motion just before entering or just after leaving the Earth's shadow provides vertical scanning through the atmosphere. Measurements taken from a tangent-height of $150 \mathrm{~km}$, where there is no attenuation, provides a self-calibration feature for every event (Thomason L.W. et al. , 2007). 
Atmos. Chem. Phys. Discuss., doi:10.5194/acp-2017-133, 2017

Manuscript under review for journal Atmos. Chem. Phys.

From the global data of SAGE II instrument recorded during the life time of the spacecraft, we filtered out the aerosol extinction data at four channels over Ethiopian region $\left(i . e, 3^{0} N-15^{0} N\right.$ and $\left.33^{0} E-48^{0} E\right)$ for the entire years and it was imported into MATLAB code then processed to calculate the stratospheric aerosol optical depth which is an input to the retrieval algorithm (Mie algorithm) which ultimately provides ASD. Then we calculated the monthly mean aerosol optical depth (AOD) from the measured extinction data by multiplying each extinction value by the level height $(i . e, 0.5 \mathrm{~km})$ for each channel. Finally, to determine the stratospheric region, the annual mean temperature profile in the same region is plotted to point the tropopause level over tropical region in general as shown in Fig. 2.

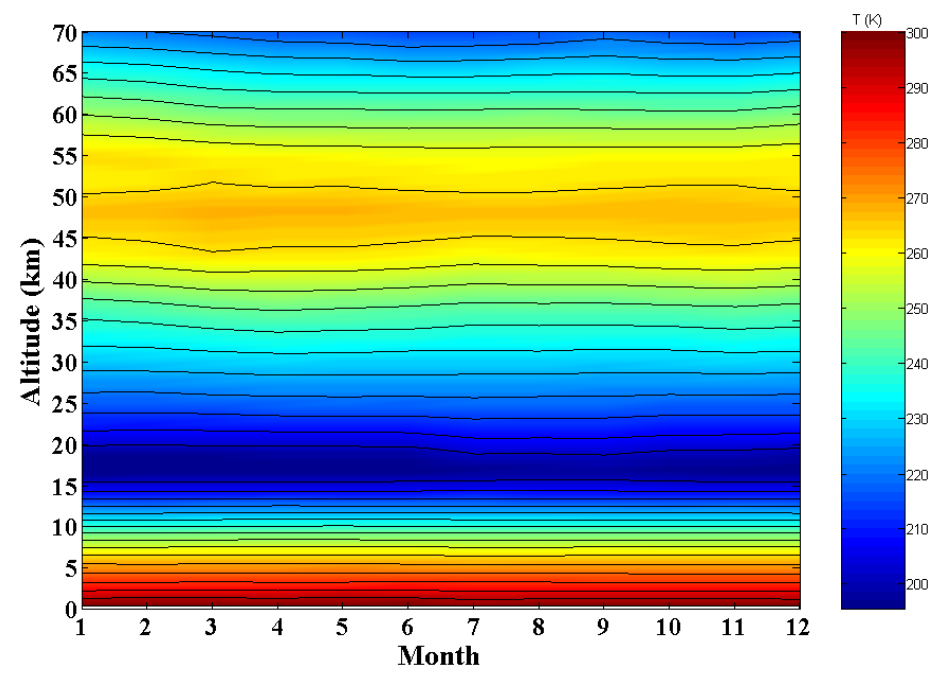

Figure 2. Monthly mean temperature profile over Ethiopia

It is common to define the tropopause level as the coldest point in the atmosphere. Accordingly the mean tropopause level over Ethiopia is located between 16 to $18 \mathrm{~km}$, as it can be seen from Fig.2. According to (Varotsos C. et al. , 2009) the height of 100hpa level is a good estimate of tropopause height in tropics. Other studies (Seok-Woo S. and Sukyoung L. , 2006) also reveal that the tropopause level of tropics is above $15 \mathrm{~km}$, which is in pretty good agreement with Fig.2. Therefore, our choice of stratospheric region (which is above $15 \mathrm{~km}$ ) is sufficient to study stratospheric aerosols over Ethiopia.

\section{Result and Discussion}

In this section, the investigated results of vertical and spectral variations, the time series of AOD and ASD for selected years of stratospheric aerosols over Ethiopia region from extinction data of SAGE II instrument aboard on ERB satellite are discussed respectively as below. The data used are (recorded during the life time of the satellite) to analyze stratospheric aerosol climatology in four different channels centered at $386 \mathrm{~nm}, 452 \mathrm{~nm}, 525 \mathrm{~nm}$ and $1020 \mathrm{~nm}$ wavelengths with a vertical resolution of 
Atmos. Chem. Phys. Discuss., doi:10.5194/acp-2017-133, 2017

Manuscript under review for journal Atmos. Chem. Phys.

Discussion started: 21 February 2017

(C) Author(s) 2017. CC-BY 3.0 License.
Atmospheric

Chemistry

and Physics

Discussions

$0.5 \mathrm{~km}$. Finally, from the coldest point of the mean temperature profile measured by SAGE II instrument, it is concluded that the tropopause level in the study area is about $17 \mathrm{~km}$ which agrees with different literatures discussed above.

\subsection{Vertical and spectral distribution of stratospheric aerosols}

Now we present the vertical and seasonal variation of aerosol extinction data from 1984 to 2005 at different channels. Fig. 3

shows the vertical distribution of monthly mean aerosol extinction values for altitude range of $15-40 \mathrm{~km}$ at $386 \mathrm{~nm}$ wavelength.

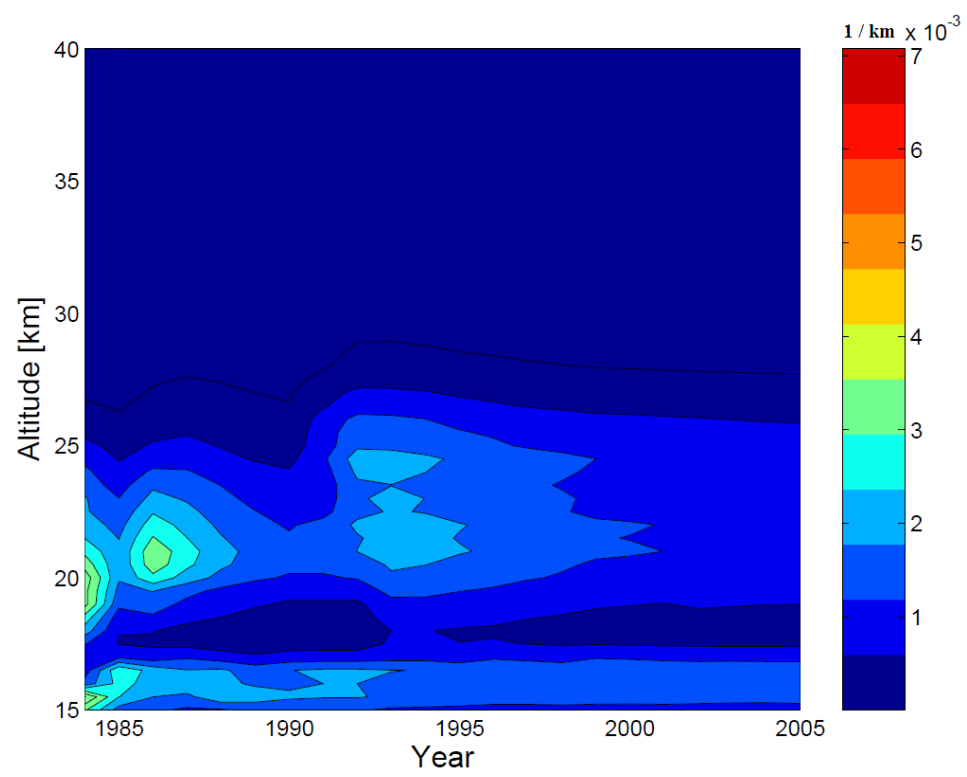

Figure 3. Vertical distribution of aerosol extinction values during measurement period at $386 \mathrm{~nm}$

As it can be seen from Fig. 3 the stratospheric aerosols show vertical and annual distribution throughout the working period of the platform, in the stratosphere. The reason is that smaller aerosols tend to rise higher in the atmosphere than larger size aerosols (depending on the nature of their source). In fact stratospheric aerosols are smaller in size so that they have longer life time in the atmosphere (Israel H. and Israel G.W. , 1974). The higher the altitude the smaller the aerosol size and the less probable to interact with clouds and to precipitate. As the extinction of light depend on the concentration of particles, the higher extinction value in our result corresponds to high concentration of aerosols which is observed about $17-25 \mathrm{~km}$. Fig. 3 also reveals that the instrument sees aerosols in the stratosphere at $386 \mathrm{~nm}$ wavelength, and cannot better see deep to the lower troposphere at this channel. The seasonal variation of columnar extinction value corresponding to the above channel is also shown in Fig. 4. 
Atmos. Chem. Phys. Discuss., doi:10.5194/acp-2017-133, 2017

Manuscript under review for journal Atmos. Chem. Phys.

Discussion started: 21 February 2017

(c) Author(s) 2017. CC-BY 3.0 License.

(c) (i)
Atmospheric 을

Chemistry

and Physics

Discussions
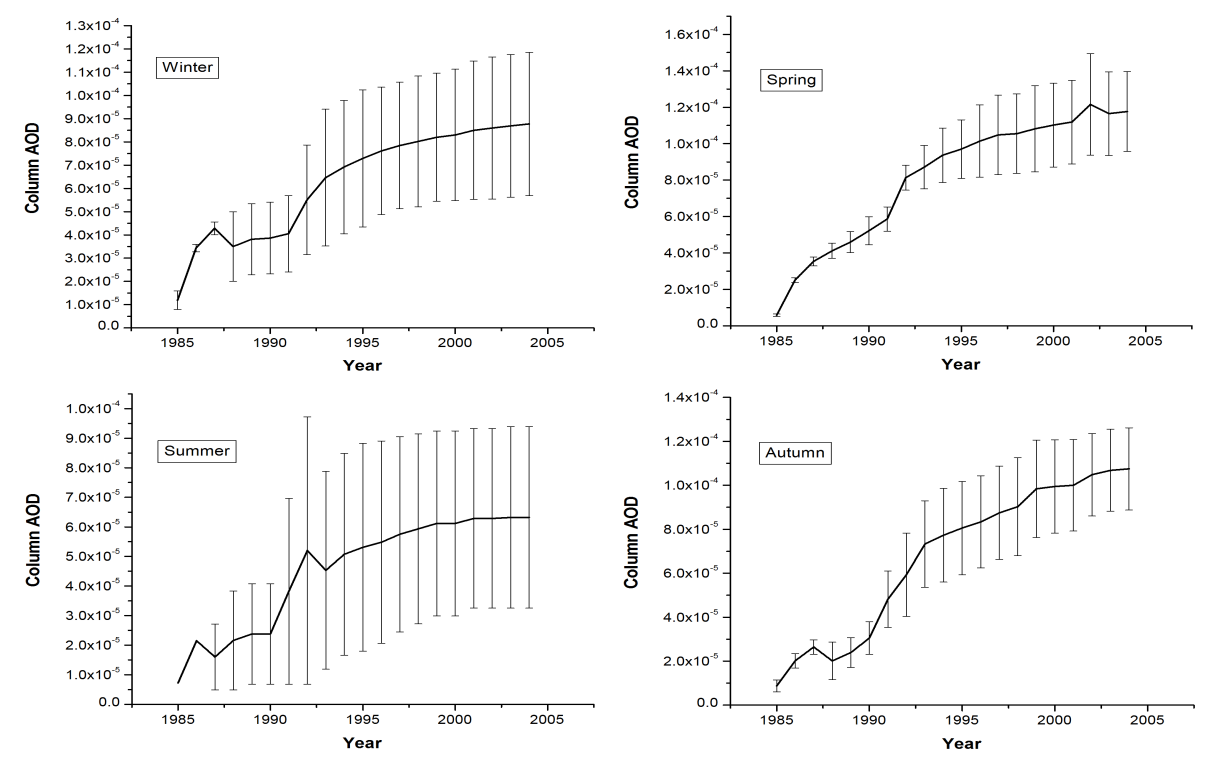

Figure 4. Seasonal variation of column AOD values at $386 \mathrm{~nm}$.

From the AOD distribution shown in Fig. 5 we can see that during some seasons (particularly Spring and Autumn) the column aerosol amount shows slight enhancements; and relatively lower concentration during Summer.

The vertical distribution of aerosol extinction values at $452 \mathrm{~nm}$ reveals almost the same feature as the $386 \mathrm{~nm}$, except the former can catch aerosols better (can see deeper up to upper troposphere).

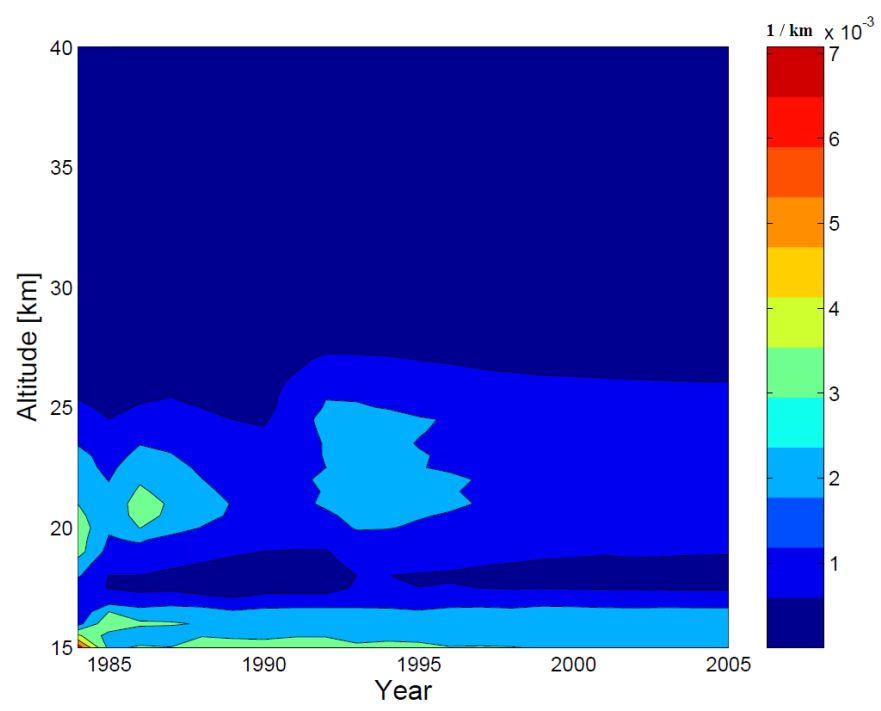

Figure 5. Vertical distribution of aerosol extinction value during measurement period at $452 \mathrm{~nm}$ 
Atmos. Chem. Phys. Discuss., doi:10.5194/acp-2017-133, 2017

Manuscript under review for journal Atmos. Chem. Phys.

From Fig. 6 we can see that the seasonal variation of mean AOD follows almost the same pattern as in the Fig. 4 except the slight increment of AOD value during all seasons at this channel.
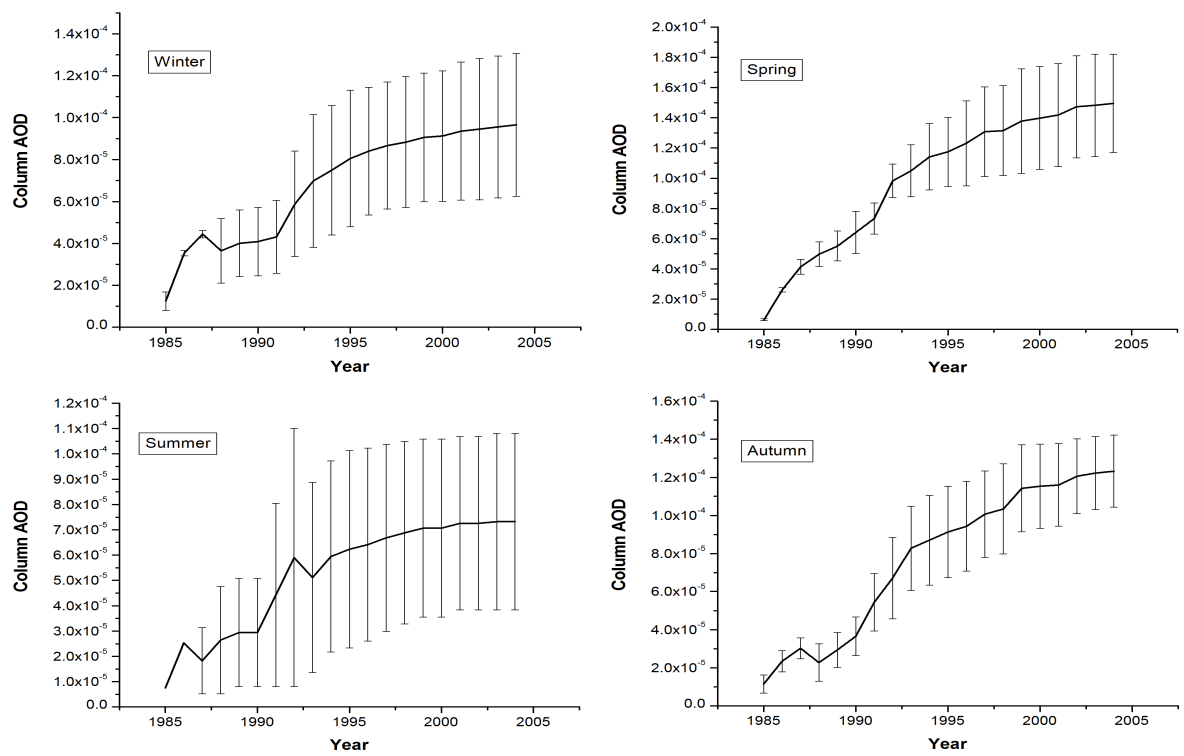

Figure 6. Seasonal variation of column AOD values at $452 \mathrm{~nm}$

Similar results of extinction values at $525 \mathrm{~nm}$ are also shown in figs. $7-8$. Figs. 5 and 7 representing vertical distribution of AOD at 452 and $525 \mathrm{~nm}$ which exhibit nearly the same feature.

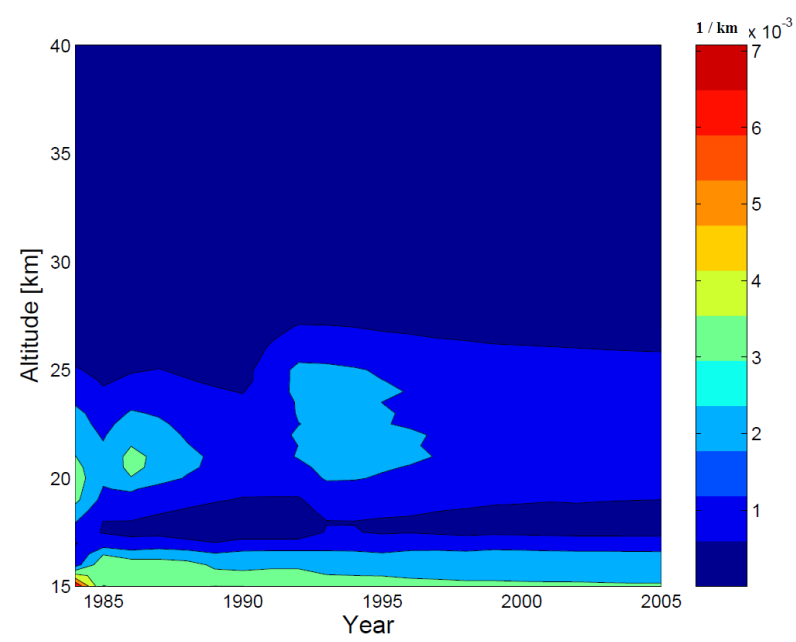

Figure 7. Vertical distribution of aerosol extinction value during measurement period at $525 \mathrm{~nm}$ 
Atmos. Chem. Phys. Discuss., doi:10.5194/acp-2017-133, 2017

Manuscript under review for journal Atmos. Chem. Phys.

Discussion started: 21 February 2017

(c) Author(s) 2017. CC-BY 3.0 License.

The seasonal variation of AOD values at $525 \mathrm{~nm}$ is also shown in Fig. 7. In this figure we can observe maximum value of AOD in the upper troposphere.
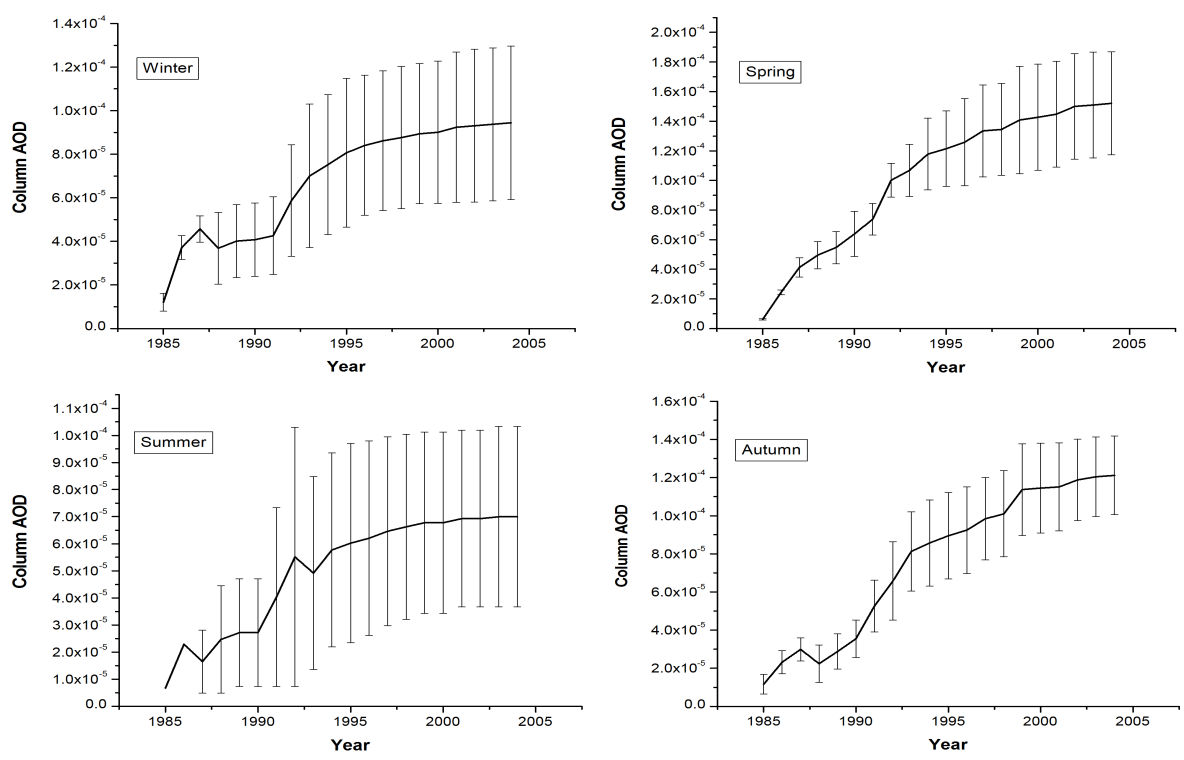

Figure 8. Seasonal variation of column AOD values at $525 \mathrm{~nm}$

The spectral variation of aerosol extinction values can be seen from the above figures. The $525 \mathrm{~nm}$ channel can capture aerosols better than the other two shorter wavelength channels in the upper troposphere because of atmospheric transmittance;

5 that is, the strong lines of water vapor and other trace gases are absent near this (visible) wavelength region, in which maximum solar radiation can reach the Earth's surface.

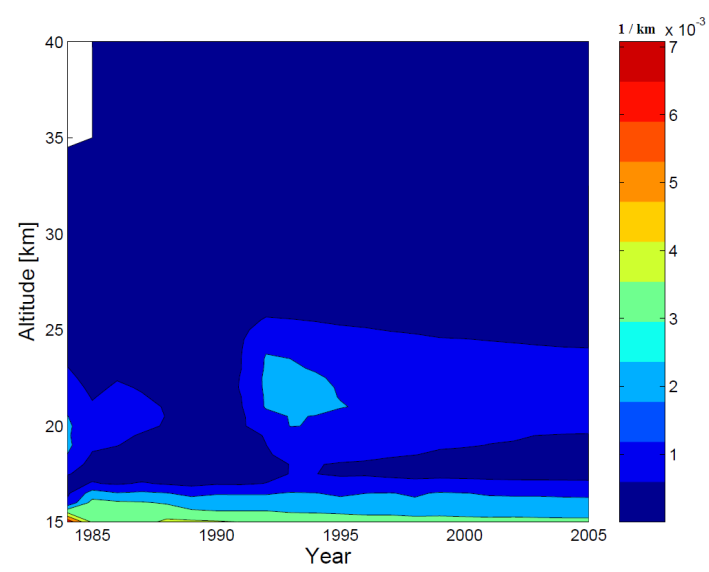

Figure 9. Vertical distribution of aerosol extinction value during measurement period at $1020 \mathrm{~nm}$ 
Atmos. Chem. Phys. Discuss., doi:10.5194/acp-2017-133, 2017

Atmospheric

Manuscript under review for journal Atmos. Chem. Phys.

Chemistry

Discussion started: 21 February 2017

(c) Author(s) 2017. CC-BY 3.0 License.

and Physics

Discussions

(c) (i)

The vertical distribution of aerosol extinction value at $1020 \mathrm{~nm}$ wavelength is also shown in Fig. 9. This channel is not too sensitive to stratospheric aerosols, as it is discussed above.

The values of the mean columnar AOD of different seasons at $1020 \mathrm{~nm}$ is shown in Fig.10 and it is not good to capture stratospheric aerosols. But it is better suited to tropospheric aerosols which are relatively larger in size. From all the figures showing the seasonal variation of aerosols, we can infer that the maximum value of AOD appears in Spring and the minimum appears in Summer.

In all plots of seasonal variation of column AOD values, aerosols show an increasing trend in all seasons during the measurement period. The abrupt increase of the column AOD values in 1991 (shown in Figs. 4, 6, 8 and 10) may be associated with the Mt.Pinatubo eruption discussed in section 3.2. As the dominant sources of stratospheric aerosol is from the troposphere the seasonal variation of AOD during the summer shows slow rate of increment as compared to other seasons. This may be due to the lower temperature of our region during this season, as temperature enhances gas to particle conversion. The $1020 \mathrm{~nm}$ wavelength represents course mode (larger) aerosol sizes which are found in the lower atmosphere as they are highly affected by gravity. Thus the stratospheric concentration and its trend at this channel changes very slowly as compared to smaller size aerosols. The vertical line shown in all plot of seasonal variation of column AOD represents the error bar. As it is clearly seen from the figures, the uncertainty of the measurement was increasing during the life time of the satellite. This may be due to the reduction of the signal count reaching the instrument after the satellite was launched (Thomason L.W. et al. , 2007). Particularly, the uncertainty is very high during the Summer season and lesser during Spring. This may be associated with the weather condition of the region as the satellite had taken no measurements during bad weather. From Figs. 6 and 8 , we can see that the $525 \mathrm{~nm}$ and $1020 \mathrm{~nm}$ wavelengths can capture upper tropospheric aerosols better than the $386 \mathrm{~nm}$ and $452 \mathrm{~nm}$ channels. According to these figures, the aerosol optical depth value is high in the troposphere, which shows high concentration of aerosols in the lower troposphere.

The seasonal variation of AOD can be associated with its sensitivity to humidity and dynamics of the atmosphere. According to (King M.D. et al. , 1980), dry and hot air inhibits cloud and rainstorm development which results in smaller values of AOD; on the other hand hot and humid air may cause AOD to increase. According to Flower et al. as mentioned in (King M.D. et al. , 1980), high turbidities (in Angstrom relation) are normally associated with high humidities characteristic of maritime tropical air masses. Low turbidities on the other hand, were found to be associated with continental polar air masses. The maximum and minimum values of AOD using SAGE II instrument over Ethiopia was attained during the seasons of winter (April specifically) and summer but we don't see them in our results as they are averaged in to seasonal values. The recent in situ measurements of AOD in Addis Ababa made by (Melaku T. , 2009) shows that dust is the dominant aerosol type over Ethiopia. Therefore, 30 the major contribution of solar extinction over Ethiopia could be due to dust aerosols. If this is so, the study of (Barkan J. et al. , 2004) supports our result, the AOD climatology over Ethiopia. The work of J. Barkan et al. (Barkan J. et al. , 2004) also points out that the major dust source over Ethiopia is found at $14.3^{0} \mathrm{~N}$ and $40.6^{0} \mathrm{E}$ which is the North-East part of Ethiopia and characterized as dry area; the active volcanic eruptions are also found in this region and it may contribute to the stratospheric AOD over Ethiopia. 
Atmos. Chem. Phys. Discuss., doi:10.5194/acp-2017-133, 2017

Manuscript under review for journal Atmos. Chem. Phys.

Discussion started: 21 February 2017

(c) Author(s) 2017. CC-BY 3.0 License.

(c) (i)
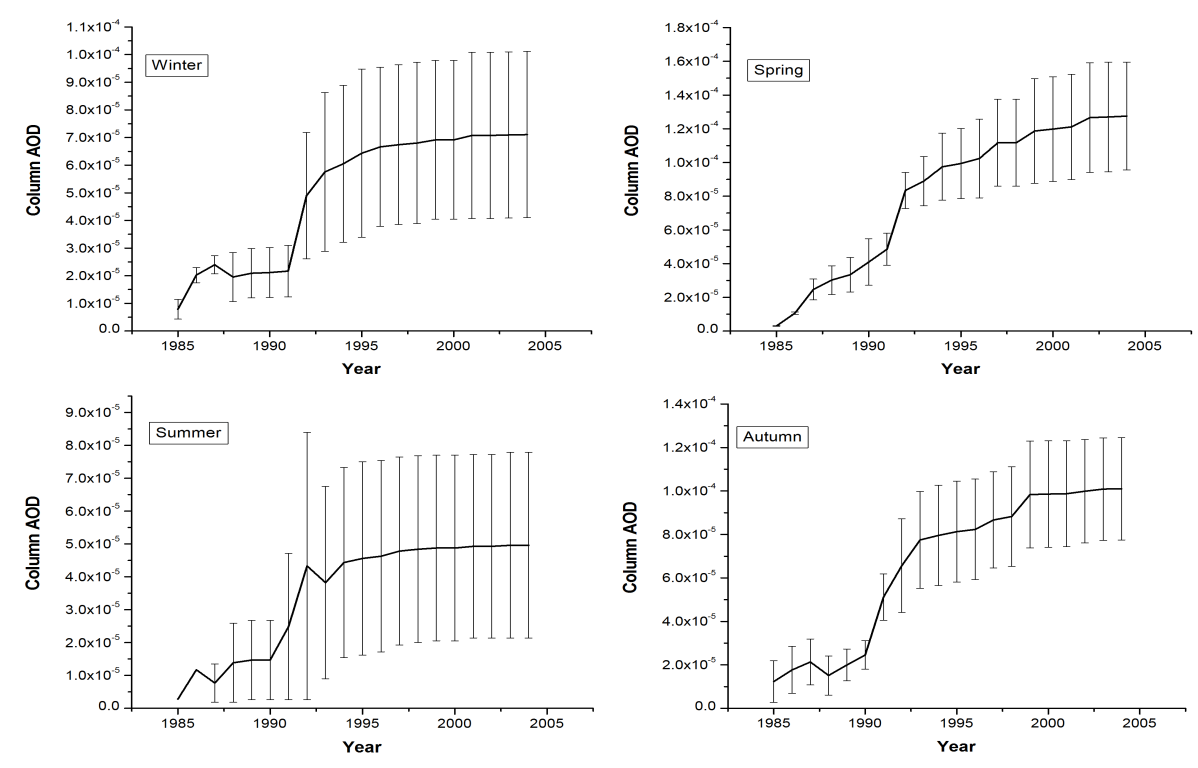

Figure 10. Seasonal variation of column AOD at $1020 \mathrm{~nm}$

\subsection{Time series of annual mean column AOD}

The annual mean value of AOD as seen by different channels over Ethiopia is shown below. We can see the 'trend' of aerosols during the life time of the SAGE II instrument.

Figure 11 shows that the mean AOD value over Ethiopia has been steadily increasing from year to year during the life time of ERBS (1984 to 2005). The increment of AOD values in all channels $(386 \mathrm{~nm}, 452 \mathrm{~nm}, 525 \mathrm{~nm}$ and $1020 \mathrm{~nm})$ indicates that both fine and course mode aerosol loading has also been increasing during this period. The reason for increment may be due to industrial development, desertification, biomass burning, different constructions, etc. The transport of aerosols from developed (industrialized) countries and active volcanic eruption areas may also result in accumulation of aerosols over less developed countries (Ethiopia). The abrupt increment of annual mean column AOD after 1991 may be associated with the Mt.Pinatubo volcanic eruption in 1991. This eruption is believed to load large aerosol mass to the stratosphere and contributed to climate change. The strong dust storms in North Africa and Asia can also be a reason for aerosol loading in Ethiopia. According to the aerosol index (AI) climatology study obtained from TOMS instrument during 1979 to 1992, the dust loading over Ethiopia shows increasing during this period, which is in good agreement with our result as dusts are the major components of aerosols over Ethiopia.

From Fig.11, we observe that the time series of aerosols show trends both before and after the 1991 historical event of Mt. Pinatubo volcanic eruption. The trend before 1991 at $525 \mathrm{~nm}$ has a slope of $7.3 \times 10^{-6}$ and the trend after 1991 has a slope of $2.1 \times 10^{-6}$. This can be associated with the reaction rate of aerosols in the stratosphere before and after the event. Thus 
Atmos. Chem. Phys. Discuss., doi:10.5194/acp-2017-133, 2017

Manuscript under review for journal Atmos. Chem. Phys.

Discussion started: 21 February 2017

(c) Author(s) 2017. CC-BY 3.0 License.
Atmospheric 옹

Chemistry

and Physics

Discussions

(c) (i)

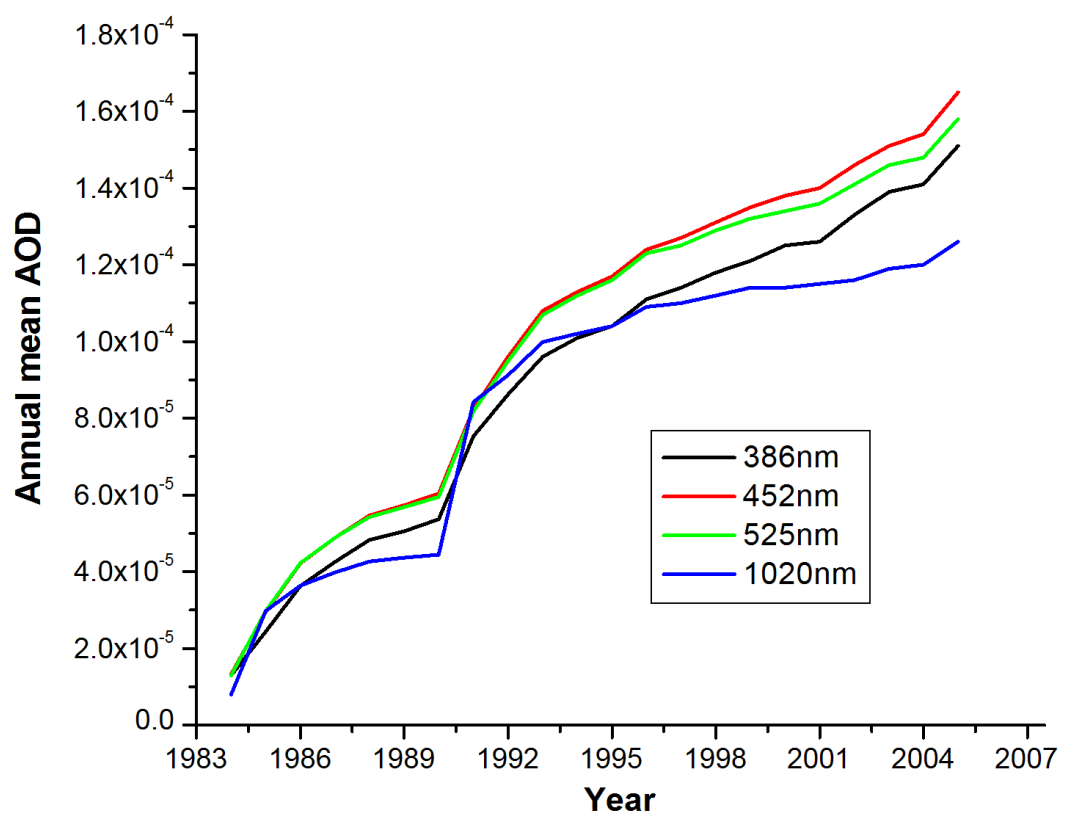

Figure 11. Annual mean column AOD at different channels

we understand that the reaction rate is higher before eruption. This also reveals that the period from 1992 to 2005 (after the eruption) is relatively volcanically quiescent period (Thomason L.W. et al. , 2007) and the higher slope before 1991 indicates there was volcanic eruption, as a result the atmosphere was not stable during that period.

\subsection{Size distribution of stratospheric aerosols}

5 Next, we shall retrieve the size distribution of aerosols using Mie retrieval algorithm based on scattering theory. The possible sources of the aerosols can also be suggested by looking for their size distribution. In this study we retrieve for the size distribution and study its relation with monthly mean value of aerosols in different years. Aerosol size distribution function for columnar aerosol optical depth is given in Fig. 11. As it is mentioned in previous sections the columnar aerosol optical depth is calculated from SAGE II data. The columnar AOD is the mean column optical depth of the measurement taken for about 21 years (from 1984 to 2005) of the Earth's Radiation Budget Satellite (ERBS). The complex refractive index we used for retrieval of size distribution is $m=1.51+i 0.005$. This is different from the real refractive index of sulfate aerosol which is about 1.45 due to the presence of different aerosol types. The value of the complex refractive index shows that the contribution of stratospheric aerosols over Ethiopia to climate is scattering, which results in cooling effect. Therefore, the net effect of stratospheric aerosols over Ethiopia is counteracting the effect of green house gases. It is well known that AOD and ASD depend on complex refractive index. This value of complex refractive index is chosen by retrieving the size distribution for different values of refractive indices by simulating aerosol optical thickness. The value of refractive index for which the square 
Atmos. Chem. Phys. Discuss., doi:10.5194/acp-2017-133, 2017

Manuscript under review for journal Atmos. Chem. Phys.

Discussion started: 21 February 2017

(C) Author(s) 2017. CC-BY 3.0 License.
Atmospheric 을

Chemistry

and Physics

Discussions

(c) (1)

of the difference between the measured and simulated aerosol optical depth (chi-squared error) is minimum provides the best guess of the refractive index. Note that at the minimum chi-squared error, the retrieval converges rapidly.

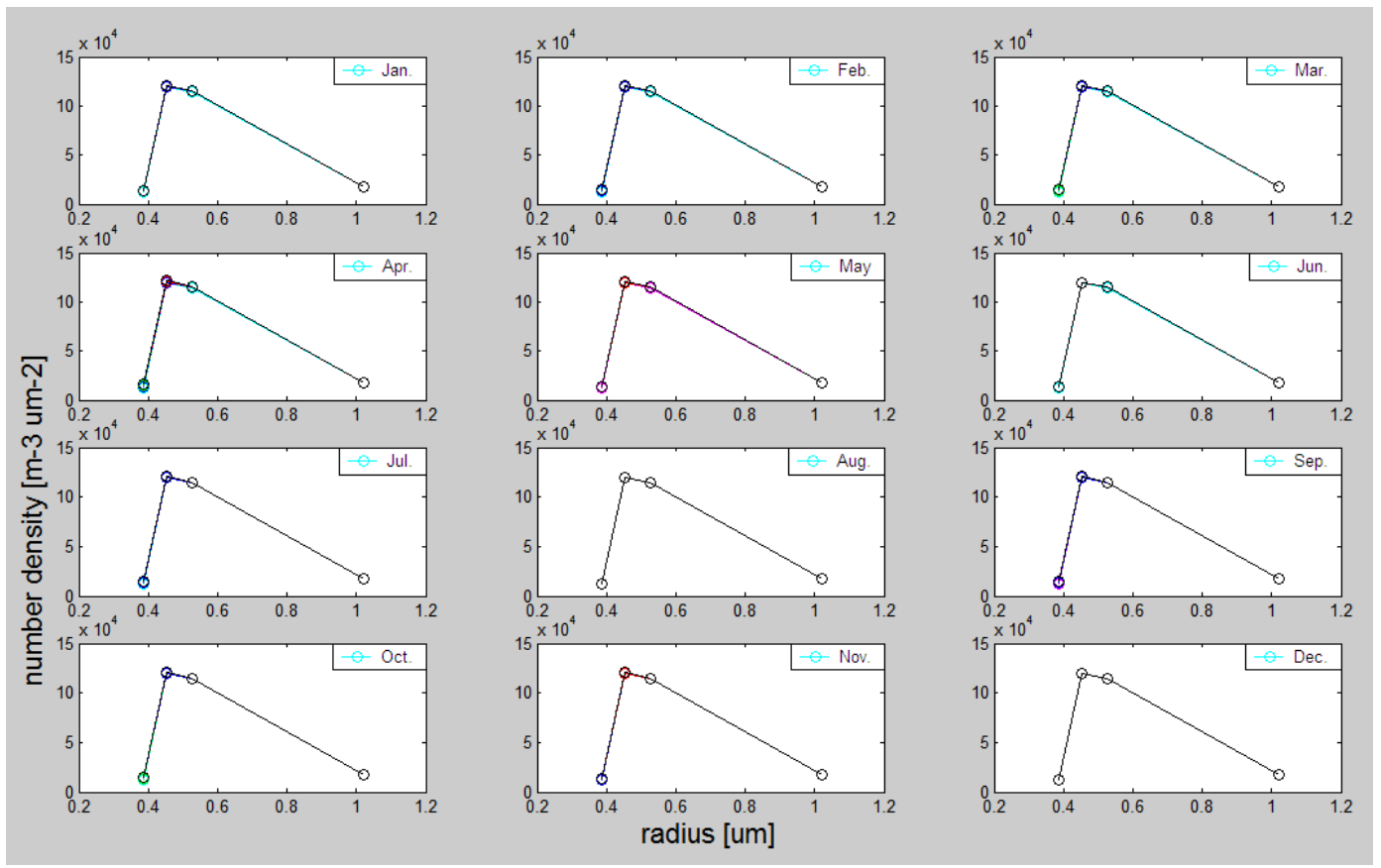

Figure 12. Monthly mean aerosol size distribution function for the years 1985, 1989, 1991, 1993, 1997 and 2004

We used the same value of complex refractive index for retrieval of climatological stratospheric size distribution of all months (January to December) of the selected years $(1985,1989,1991,1993,1997$ and 2004) because the stratosphere is more stable and the aerosols are long-lived in the stratosphere relative to troposphere. From the retrieved aerosol size distribution function one can suspect the production mechanisms of atmospheric aerosol. According to (King M.D. et al. , 1978), those particles with radii $\leq 0.5 \mu \mathrm{m}$ are produced by a combination of nucleation from the gas phase and subsequent coagulation. Particles having radii $\geq 1.0 \mu \mathrm{m}$ are principally the result of mechanical and wind stresses at the Earth's surface. From the aerosol physics, these production mechanisms are not very effective in the $0.5-1.0 \mu m$ range (King M.D. et al. , 1978). Therefore, the size distribution climatology shown in Fig. 12 can be divided into two components. The smaller particles can be given by the Jung distribution, but the multi-modal nature of size distribution is more appropriate to capture all sizes of aerosol. One can see the relation between the columnar aerosol optical depth and aerosol size distribution by comparing the seasonal mean AOD values (shown in Fig. 4 to Fig.10) for different channels with Fig. 12. It is known that the maximum AOD shows maximum loading of aerosols or high concentration of aerosols as expected. As a result the ASD function shows maximum number density in April (though the difference is not significant to be shown in Fig. 12 as the average AOD of six different years indicated above is 
Atmos. Chem. Phys. Discuss., doi:10.5194/acp-2017-133, 2017

Manuscript under review for journal Atmos. Chem. Phys.

Discussion started: 21 February 2017

(c) Author(s) 2017. CC-BY 3.0 License.

(c) (i)
Atmospheric

Chemistry

and Physics

Discussions

used). This can be associated with the seasonal variation of columnar AOD. As a consequence the ASD function doesn't show a trend.

\section{Conclusions}

In this article the vertical and spectral variation of stratospheric aerosol extinction, seasonal variation of AOD, time series of

5 total column AOD and retrieval of its corresponding size distribution over the study area are presented. Aerosol climatology for such a long period of time over Ethiopian region is the first to be presented.

From the stratospheric aerosol extinction data at four channels $(386 \mathrm{~nm}, 452 \mathrm{~nm}, 525 \mathrm{~nm}$, and1020 $\mathrm{nm})$ discussed in this paper it is observed that the first three channels show high stratospheric extinction between $(17-25) \mathrm{km}$, indicating high concentration of aerosols around this altitude. But, the forth channel is not as good as the rest to capture stratospheric aerosols, though it captures aerosols found in lower atmosphere.

The annual mean column value of AOD as seen by different channels shows the trend of AOD increment (aerosol loading) and seasonal variation, over Ethiopia during the measurement period in all channels. This indicates that both fine and course mode aerosol loading had also been nearly steadily increasing during this period and in a good agreement with the results of $\mathrm{J}$. Barkan (2004) on dust aerosol index climatology with TOMS instrument.

15 The ASD function used to model the particulate matters is Jung distribution having a refractive index of $m=1.51+i 0.005$. The value of the complex refractive index shows that the contribution of stratospheric aerosols over Ethiopia to climate is scattering the incoming solar irradiance which results in cooling effect that counteracts the effect of greenhouse gases. As a result the aerosols reduce the incoming solar irradiance to the ground.

The ASD results suggest the origin of the particulate maters in the region may be mechanical source combined with gas to particle conversion in the stratosphere with the dominant size distribution in the range of $(0.452-0.525) \mu m$ radius. 
Atmos. Chem. Phys. Discuss., doi:10.5194/acp-2017-133, 2017

Manuscript under review for journal Atmos. Chem. Phys.

Discussion started: 21 February 2017

(c) Author(s) 2017. CC-BY 3.0 License.
Atmospheric

Chemistry

and Physics

Discussions

(c) (1)

\section{References}

Barkan J. et al. (2004). Climatology of Dust Sources in North Africa and the Arabian Peninsula, Based on TOMS data. Indoor Built Environ., 13, 407-419.

CCSP. (2006). Aerosol Properties and their Impacts on Climate: U.S. Climate Change Science Program, 5-year Assessment Review, Syn-

5 thensis and Assessment Product 2.3 .

Chowdhary J. and Cairs B. (2002). Case Studies of Aerosol Retrievals over the Ocean from Multiangle, Multispectral Photometric Remote Sensing Data.

Fu Q.. et al. (1999). Aerosol Direct Radiative Forcing: A Five year Climatology at the ARM SGP CART site . Ninth ARM Science Team Meeting Proceedings. San Antonio, Texas.

Hobbs P.V. (1993). Aerosol-Cloud-Climate Interactions. University of Washington,Seattel, Washington: Acadamic Press Inc., Harcourt Brace and Company.

Israel H. and Israel G.W. (1974). Trace Elements in the Atmosphere. Ann Arbor, Michigan.

King M.D. et al. (1980). Spectral Variation of Optical Depth at Tucson, Arizona between August 1975 and December 1977. Journal of Applied Meteorology, 19, 723- 732 .

15 King M.D. et al. (1978). Aerosol Size Distributions Obtained by Inversion of Spectral Optical Depth Measurements. J. Atmos. Sci., 35, 2153-2167.

Melaku T. (2009). Retrieval of Atmospheric Aerosol Optical and Microphysical Parameters from Ground Based Passive and Active Remote Sensing Measurements, MSc. thesis, Physics Department, Addis Ababa university.

Sayer A.M. (2006). Aerosol Remote Sensing using AATSR. Department of Physics, University of Oxford: Atmospheric, Oceanic and Planetary Physics.

Seok-Woo S. and Sukyoung L. (2006). Intraseasonal Variability of the Zonal-Mean Tropical Tropopause Height . American Meterological Society, 64, 2695-2706.

Thomason L. et al. (2007). Report on the Assessment of Stratospheric Aerosol Properties: New Data Record, but no Trend.

Thomason L.W. et al. (2007). SAGE II Measurements of Stratospheric Aerosol Properties at Non-Volcanic Levels . Atmos. Chem. Phys.

Discuss., 7, 6959-6997.

Tzanis C. and Varotsos C.A.: Tropospheric Aerosol Forcing of Climate: a case study for the greater area of Greece. International Journal of Remote Sensing, 29(9), 2507-2517,2008.

Varotsos C. et al. (2009). Scaling Behaviour of the global Tropopause. Atmos.Chem.Phys., 9, 677-683. 